Curr Treat Options Neurol. 2014 July ; 16(7): 301. doi:10.1007/s11940-014-0301-x.

\title{
Management of Pediatric Status Epilepticus
}

Nicholas Abend, MD and

Departments of Neurology and Pediatrics, The Children's Hospital of Philadelphia and the Perelman School of Medicine at the University of Pennsylvania (Philadelphia, PA)

\section{Tobias Loddenkemper, MD}

Division of Epilepsy and Clinical Neurophysiology, Department of Neurology, Boston, Children's Hospital and Harvard Medical School (Boston, MA)

Nicholas Abend: ABEND@email.chop.edu; Tobias Loddenkemper: Tobias.Loddenkemper@childrens.harvard.edu

\section{Opinion Statement}

\begin{abstract}
Status epilepticus (SE) is a medical emergency consisting of persistent or recurring seizures without a return to baseline mental status. SE is not a single entity, but can be divided into subtypes based on seizure types and underlying etiologies. Management should be implemented rapidly and based on continuously reassessed care pathways. The aim is to terminate seizures while simultaneously identifying and managing precipitant conditions. Seizure management involves "emergent" treatment with benzodiazepines (lorazepam intravenously, midazolam intramuscularly, or diazepam rectally) followed by "urgent" therapy (phenytoin/fosphenytoin, phenobarbital, levetiracetam or valproate sodium). If seizures persist, "refractory" treatments include infusions of midazolam or pentobarbital. Prognosis is dependent on the underlying etiology and seizure persistence. This paper reviews the current management options and strategies for pediatric convulsive status epilepticus.
\end{abstract}

\section{Keywords}

Status epilepticus; SE; Seizure; Pediatric; Management

\section{Introduction}

The most recent Neurocritical Care Society guideline for status epilepticus (SE) management in children and adults defines SE as " 5 minutes or more of (i) continuous clinical and/or electrographic seizure activity or (ii) recurrent seizure activity without recovery (returning to baseline) between seizures."[1] Refractory status epilepticus (RSE) is defined as clinical or electrographic seizures which persist after an adequate dose of an initial benzodiazepine and a second appropriate anti-seizure medication. In contrast to some earlier SE definitions, the current guideline definitions (1) shorten the seizure duration required for SE diagnosis and thereby prompt more rapid initial aggressive management, (2)

Correspondence to: Nicholas Abend, ABEND@email . chop. edu.

Human and Animal Rights and Informed Consent

This article does not contain any studies with human or animal subjects performed by any of the authors 
eliminate any seizure duration requirement from the RSE definition and thereby enable rapid progression through management steps, and (3) indicate that clinical and electrographic-only seizures should be equally targeted for emergency management and thereby encourage increased use of EEG monitoring to identify and manage electrographic-only seizures if they persist after clinically-evident seizures terminate.

\section{Overall Management Approach}

Initial SE management should involve resuscitation and an evaluation to identify any acute symptomatic SE etiologies.[1,2] The Neurocritical Care Society guideline provides a critical care treatment outline. These steps include non-invasive airway protection and gas exchange with head positioning (0-2 minutes), intubation if airway or gas exchange is compromised or intracranial pressure is elevated (0-10 minutes), vital signs assessment (0-2 minutes), vasopressor support if needed (5-15 minutes), neurologic examination (0-5 minutes), and placement of peripheral intravenous access for administration of emergent anti-seizure medication therapy and fluid resuscitation ( $0-5$ minutes). Initial etiologic testing should include bedside finger stick blood glucose ( $0-2$ minutes), and lab testing including blood glucose, complete blood count, basic metabolic panel, calcium, magnesium, and antiseizure medication levels (5 minutes). Depending on the clinical scenario, other diagnostic testing may be required such as neuroimaging or lumbar puncture ( $0-60$ minutes), other laboratory testing (including liver function tests, coagulation studies, arterial blood gas, toxicology screen, and inborn errors of metabolism screening), and continuous EEG monitoring if the patient is not waking up after clinical seizures cease (15-60 minutes).[1]

Evaluating for precipitating etiologies is critical since 15-20\% of children presenting with convulsive SE will have acute symptomatic etiologies identified.[3-5][Class IV] The American Academy of Neurology practice parameter addressing the diagnostic assessment of a child with convulsive SE summarized data regarding testing. Among children who underwent testing, various abnormalities were identified including low anticonvulsant levels (32\%), neuroimaging abnormalities (8\%), electrolytes (6\%), inborn errors of metabolism (4.2\%), ingestion (3.6\%), CNS infection (2.8\%), and positive blood cultures (2.5\%).[2] A prospective observational study of 144 children presenting with convulsive SE reported that combined CT and MRI provided a diagnosis in $30 \%$ of children. Among 44 children who underwent head CT and MRI, 14 had a normal head CT but an abnormal MRI, leading to the conclusion that MRI had a superior yield and should be considered whenever available if head CT is non-diagnostic.[3][Class IV] Some centers use rapid sequence MRI as a first line imaging modality if it is available and feasible for a given child to avoid CT radiation.

Medication management aims to terminate clinical and electrographic seizures. The guideline states that "definitive control of SE should be established within 60 minutes of onset."'[1] In contrast to some earlier SE management algorithms which considered medications as first, second, and third line agents, the new guideline uses the terms emergent, urgent, and refractory to help convey a sense of time urgency. Medications used for management are discussed in more detail below. 
The guideline emphasizes the need for rapid management due to increasing animal model evidence that prolonged seizures cause neuronal injury and are associated with an increased risk for subsequent epilepsy and unfavorable behavioral and cognitive outcomes. Further, there is increasing clinical evidence that persisting seizures become more self-sustaining and pharmacoresistant. An observational study of 157 children with seizures lasting longer than 5 minutes reported that treatment delays exceeding 30 minutes were associated with delays in achieving seizure control.[6][Class IV] An observational study of 27 children documented that first and second line medications were effective in terminating SE in $86 \%$ of subjects when seizure duration was less than 20 minutes at presentation and only $15 \%$ of subjects when seizure duration exceeded 30 minutes.[7][Class IV] A retrospective study of 358 children found that midazolam efficacy was significantly lower when treatment was initiated more than 3 hours after seizure onset, and there was a trend toward reduced efficacy even at 1 hour.[8][Class IV] These findings may be explained by data indicating that with continuing seizures, inhibitory gamma-aminobutyric acid receptors are internalized, resulting decreased inhibitory control. $[9,10]$

There are two main indications for performing urgent EEG. First, if psychogenic status epilepticus is suspected then diagnosis using EEG monitoring may avoid continued exposure to anticonvulsant medications and pharmacologic coma induction with potential adverse effects.[11, 12][Class IV] Second, there is increasing data that after convulsive SE terminates, some patients have persisting EEG-only (non-convulsive) seizures. These may occur when convulsive seizures terminate with anticonvulsant administration but EEG seizures persist (electroclinical uncoupling or dissociation), or when paralytics are required as part of the management strategy and clinically-evident convulsions are thereby masked. The recent SE management guideline states that in order to identify electrographic seizures, "continuous electroencephalographic monitoring should be initiated within one hour of status epilepticus onset if ongoing seizures are suspected." The guideline recommends 48 hours of EEG monitoring to identify possible non-convulsive seizures in children with recent SE with return to baseline mental status in 10 minutes, in patients with known acute symptomatic brain injury including traumatic brain injury, stroke, coma after cardiac arrest, or in patients with altered mental status.[1][Class I, Level B evidence] Observational studies have reported that electrographic seizures in critically ill children, particularly those with a high seizure burden, are associated with worse short and long term outcomes, including multivariable analyses that have adjusted for variables such as etiology and critical illness severity.[13-17][Class IV] Observational studies of critically ill children have identified electrographic seizures by EEG monitoring among critically ill children who had presented with convulsive SE.[15, 18][Class IV] A multi-center retrospective study of 122 subjects who underwent EEG monitoring concluded that the likelihood of experiencing an electrographic seizure was five times higher among children who presented with convulsive SE.[19][Class IV] A multi-center study of 550 children who underwent EEG monitoring while in the ICU included 98 subjects who had presented with convulsive SE. Electrographic seizures (with or without clinical correlate) were identified in $33 \%$ of subjects. Among those with seizures, $34 \%$ had exclusively EEG-only seizures which would not have been identified without EEG monitoring. Further, the seizure burden was often. Among those with electrographic seizures identified 47\% had electrographic status 
epilepticus. Risk factors for identifying seizures on EEG monitoring included a prior diagnosis of epilepsy and the presence of inter-ictal epileptiform discharges.[20][Class IV] These studies all included children who underwent continuous EEG monitoring, and studies have not prospectively evaluated consecutive patients after convulsive SE termination to determine the true incidence or risk factors for persisting electrographic seizures. Additionally, further study is needed to determine whether aggressive identification and management of electrographic seizures improves outcome.

While evidence-based pathways are not available and some variation occurs in SE management, [21] there is increasing data indicating the importance of a management plan to expedite therapeutic decisions and avoid treatment delays. A recent consensus document stressed the importance of written protocol which provide a clear structured time frame.[22] One study evaluating the management of children with convulsive SE reported that laboratory parameters were often not checked and long delays often occurred in obtaining glucose results when it was checked.[23][Class IV] Anticonvulsant management in children with convulsive SE is often delayed or involves dosing outside of recommended guidelines. A retrospective multi-center study reported that even once in the emergency department, the median time to administer a second-line anticonvulsant to a seizing child was 24 minutes. [24][Class IV] Benzodiazepine dosing has been reported to be outside usual dosing guidelines in $23 \%$ of children with convulsive SE.[23][Class IV] Excess benzodiazepine dosing, which often occurs when prehospital doses have been administered, contributes to respiratory insufficiency and need for intensive care unit admission.[23, 25, 26][Class IV]

\section{Benzodiazepines}

Benzodiazepines are the emergent medications of choice, with specific benzodiazepines determined by the available route of administration; lorazepam for intravenous administration, midazolam for intramuscular or intranasal administration, and diazepam for rectal administration.[1] Repeat dosing may be provided in 5-10 minutes if needed.

However, care should be taken to assess whether any pre-hospital benzodiazepines were administered in which case progressing to the next urgent medication may be indicated. Lorazepam may be administered intravenously at $0.1 \mathrm{mg} / \mathrm{kg}$ with a repeat dose in 5 minutes, up to a maximum dose of $4 \mathrm{mg}$. Diazepam may be administered intravenously at $0.15 \mathrm{mg} / \mathrm{kg}$ with a repeat dose in 5 minutes, up to a maximum dose of $10 \mathrm{mg}$. If no intravenous access is available, midazolam may be administered intramuscularly (5mg for 13-40 $\mathrm{kg}$ body weight or $10 \mathrm{mg}$ for $>40 \mathrm{~kg}$ body weight $)$ or intranasally $(0.2 \mathrm{mg} / \mathrm{kg})$ or buccally $(0.5 \mathrm{mg} / \mathrm{kg})$.

Midazolam is not approved by the Federal Drug Administration for intranasal or buccal use.

The two most common intravenous benzodiazepine options are intravenous lorazepam and diazepam. In a prospective trial, 78 children with SE were randomized to receive either intravenous lorazepam $(0.1 \mathrm{mg} / \mathrm{kg})$ or intravenous diazepam $(0.2 \mathrm{mg} / \mathrm{kg})$ plus phenytoin $(18 \mathrm{mg} / \mathrm{kg})$ and there was no difference in terms of median time to seizure termination.[27] Meta-analyses have indicated that intravenous lorazepam is at least as effective as intravenous diazepam and is associated with fewer adverse events in the treatment of acute tonic-clonic convulsions[28][Class IV] and that midazolam administered by any route was superior to diazepam administered by any route.[29][Class IV]

Curr Treat Options Neurol. Author manuscript; available in PMC 2015 July 01. 
Adverse effects for all these benzodiazepines include sedation, respiratory depression, and hypotension. The recent status epilepticus guideline considers lorazepam and midazolam to be emergent treatments (Class I, level A evidence) and diazepam to be an emergent treatment (Class IIa, Level A evidence).[1]

Since benzodiazepines are relatively short acting, unless the SE etiology has been identified and definitively corrected, all children should also receive an urgent work up for underlying etiologies (see below) in addition to a benzodiazepine.[1]

\section{Phenytoin and Fosphenytoin}

Overview: Phenytoin stabilizes the inactive form of the neuronal voltage-gated sodium channels and thereby limits repetitive firing of action potentials. Phenytoin and fosphenytoin are available in oral and intravenous forms, respectively, and fosphenytoin can also be administered intramuscularly. Fosphenytoin is a water soluble pro-drug that is rapidly and entirely converted to phenytoin.

Role and Standard Dosage: The recent status epilepticus guideline considers phenytoin/ fosphenytoin to be emergent treatment options (Class IIb, Level A evidence), urgent treatment options (Class IIA, Level B evidence), and refractory treatment options (Class IIB, Level C evidence) with dosing of $20 \mathrm{mg} / \mathrm{kg}$ followed by another $5-10 \mathrm{mg} / \mathrm{kg}$ if needed.[1] Fosphenytoin is dosed in phenytoin equivalents. A randomized controlled trial of 178 children with SE compared lorazepam $(0.1 \mathrm{mg} / \mathrm{kg})$ versus diazepam $(0.2 \mathrm{mg} / \mathrm{kg})$ and phenytoin $(18 \mathrm{mg} / \mathrm{kg})$ and reported $100 \%$ success with both treatments. No patients required additional anticonvulsants. Respiratory depression occurred in 4-6\% and was similar in both groups.[27][class II]

Adverse Effects: Bradyarrhythmias, hypotension, local tissue necrosis (including purple glove syndrome). There is a black box warning that rapid infusion increases the risk of cardiovascular adverse effects. Fosphenytoin has a lower risk of cardiovascular adverse effects and does not cause tissue injury including necrosis if it extravasates.

Interactions: Strong hepatic P450 enzyme inducer and highly protein bound.

\section{Phenobarbital}

Overview: Phenobarbital is a long-acting barbiturate that enhances gamma-aminobutyric acid (GABA)-mediated inhibition.

Role and Standard Dosage: The recent status epilepticus guideline considers phenobarbital to be an emergent treatment option (Class IIB, Level A evidence), an urgent control treatment option (Class IIB, Level C evidence) and a refractory treatment option (Class IIB, Level C evidence) with dosing of $20 \mathrm{mg} / \mathrm{kg}$ followed by another $5-10 \mathrm{mg} / \mathrm{kg}$ if needed.[1] A prospective study of 36 children with SE indicated that phenobarbital stopped seizures faster than a combination of diazepam and phenytoin and safety was similar.[30][Class IV]

Several reports have described the use of high dose phenobarbital. A retrospective series of 50 children with RSE treated with high dose phenobarbital to achieve serum levels of up to 
$1481 \mathrm{uM} / 1$ reported that seizures were controlled in $94 \%$. Intubations were common but hypotension was unusual and mild.[31][Class IV] A case series of 16 children with SE received enteral phenobarbital at doses ranging from $20-80 \mathrm{mg} / \mathrm{kg}$ and reported seizure control within 1 hour without any adverse effects.[32][Class IV] A case series included 3 children with RSE whose seizures were controlled after administration of high dose phenobarbital, which achieved serum levels of $60-80 \mathrm{ug} / \mathrm{mL}$.[33][Class IV]

Adverse Effects: Sedation, respiratory depression including need for ventilation, and hypotension. Cardiovascular and respiratory monitoring is generally required.

Contraindications: Phenobarbital can worsen porphyria.

Interactions: Strong hepatic enzyme inducer.

\section{Valproic Acid}

Overview: Valproic acid is a broad spectrum anticonvulsant that modulates sodium and calcium channels, as well as inhibitory GABAergic neurotransmission. Valproic acid is available in oral and intravenous formulations.

Role and Standard Dosage: The recent status epilepticus guideline considers valproic acid to be an emergent treatment option (Class IIB, Level A evidence), an urgent control treatment option (Class IIA, Level A evidence) and a refractory treatment option (Class IIA, Level B evidence) with dosing of $20-40 \mathrm{mg} / \mathrm{kg}$.[1] An open-label randomized controlled study compared 40 children with RSE randomized to receive intravenous sodium valproate (loading dose of $30 \mathrm{mg} / \mathrm{kg}$ ) or diazepam. RSE was controlled in $80 \%$ of the valproate-treated subjects in a median time of 5 minutes and $85 \%$ of the diazepam subjects in a median time of 17 minutes. None of the patients in the valproate group required ventilation or developed hypotension while in the diazepam group $60 \%$ of subjects required ventilation and $50 \%$ developed hypotension.[34][Class II] A study of 18 children who received valproate loading doses of $25 \mathrm{mg} / \mathrm{kg}$ reported $100 \%$ seizure termination within 30 minutes with no adverse effects. [35][Class IV] A study of 41 children who received valproate loading doses of 20-40 $\mathrm{mg} / \mathrm{kg}$ followed by infusions at $5 \mathrm{mg} / \mathrm{kg} /$ hour reported termination of clinical and EEG seizures in 78\%, with $66 \%$ achieving control within 6 minutes.[36].[Class IV]

Contraindications: Contraindicated in patients with active hepatitis, pancreatitis, or known or suspected mitochondrial disease.

Adverse Effects: Black box warnings include hepatotoxicity (highest risk in children less than two years of age, those receiving anticonvulsant polytherapy, and children with mitochondrial disorders), pancreatitis, and teratogenicity. Other adverse effects include pancytopenia, thrombocytopenia, platelet dysfunction, hypersensitivity reactions including Stevens-Johnson syndrome and toxic epidermal necrolysis), and encephalopathy (with or without elevated ammonia).

Interactions: Hepatic enzyme inhibitor and competes with other protein bound drugs.

Curr Treat Options Neurol. Author manuscript; available in PMC 2015 July 01. 


\section{Levetiracetam}

Overview: Levetiracetam is a broad spectrum anticonvulsant and the exact anticonvulsant mechanism remains unknown. Levetiracetam is not metabolized by the liver, has low protein binding, and is excreted renally. Levetiracetam is available in oral and intravenous forms.

Role and Standard Dosage: The recent status epilepticus guideline considers levetiracetam to be an urgent therapy option (Class IIB, Level C evidence) and suggests dosing of 20-60 $\mathrm{mg} / \mathrm{kg}$.[1] Only observational and retrospective series are available. An observational study described 45 children who received intravenous levetiracetam for acute repeated seizures and status epilepticus at a median initial dose of $14 \mathrm{mg} / \mathrm{kg}$ (range $5-30 \mathrm{mg} / \mathrm{kg}$ ). Levetiracetam terminated acute repetitive seizures in $59 \%$ of 39 subjects, convulsive status epilepticus in $75 \%$ of 4 subjects, and non-convulsive status epilepticus in $100 \%$ of 2 subjects without any major adverse effects.[37][Class IV] A retrospective study described 73 children who received levetiracetam within 30 minutes of a seizure including serial seizures in $79 \%$, single seizures in $12 \%$, and status epilepticus in $8 \%$. At one hour, $89 \%$ of subjects were seizure free and there were no major adverse events.[38][Class IV] A series of 32 children treated with intravenous levetiracetam $(50 \mathrm{mg} / \mathrm{kg}$ over 15 minutes) for acute seizures included 16 subjects with SE, all of whom had seizure termination within 25-30 minutes of infusion without adverse effects.[39][Class IV]

Adverse Effects: Sedation and irritability.

\section{Topiramate}

Overview: Topiramate is a broad spectrum anticonvulsant with multiple mechanisms of action including blockage of kainate/AMPA glutamate receptors, blockage of voltage-gated sodium channels, enhanced GABA-mediated chloride flux, reduction in voltage-activated calcium currents, and activation of potassium currents. Topiramate is only available in an oral formulation, but it can be crushed and administered via nasogastric tube.

Role and Standard Dosage: The recent status epilepticus guideline considers topiramate to be used as a refractory treatment option (Class IIB, Level C evidence) with unestablished dosing in children.[1] Only case series have described the use of topiramate for RSE with initial doses of 5-10 mg/kg that were escalated to doses of about $25 \mathrm{mg} / \mathrm{kg}$. The largest case series included 14 children with RSE receiving high dose suppressive therapy and adjuvant topiramate. After administration of an initial dose of $5 \mathrm{mg} / \mathrm{kg} /$ day and subsequent $5 \mathrm{mg} / \mathrm{kg} /$ day divided twice daily, $64 \%$ of children had seizure termination. An additional three children had a reduction in seizures after escalation to $25 \mathrm{mg} / \mathrm{kg} /$ day over 72 hours. Eleven patients could be weaned from high dose suppressive medications. Mild metabolic acidosis occurred in three children who were receiving doses of $15-25 \mathrm{~m} / \mathrm{kg} / \mathrm{day}$. Six of the topiramate responders with follow-up data available were normal or had only minor declines on cognitive function.[40][Class IV]

Adverse Effects: Metabolic acidosis, increased intraocular pressure, oligohydrosis resulting in hyperthermia, and nephrolithiasis. 
Interactions: Hepatic metabolism is low when administered without enzyme inducing medications but may increase with co-administration of enzyme inducing medications such as phenytoin or phenobarbital leading to a shorter half-life.

\section{Midazolam}

Overview: Midazolam is an injectable benzodiazepine that is fast acting, rapidly penetrates the blood brain barrier, and has a short duration of action. It modulates GABA receptors, which suppress neuronal excitability.

Role and Standard Dosage: The recent status epilepticus guideline considers midazolam as a refractory treatment option (Class IIA, Level B evidence).[1] Dosing usually involves an initial loading dose of $0.2 \mathrm{mg} / \mathrm{kg}$ followed by an infusion at $0.05-2 \mathrm{mg} / \mathrm{kg} /$ hour titrated as needed to achieve clinical or electrographic seizure suppression or EEG burst suppression. A meta-analysis of 111 children indicated that midazolam was as effective as other coma inducing medications and had lower mortality (zero with midazolam).[41][Class IV] A multi-center, retrospective study suggested efficacy of both midazolam boluses and continuous infusion.[8][Class IV] An open label randomized study comparing midazolam and diazepam in 40 children indicated similar efficacy ( $86 \%$ and $89 \%$ respectively), but midazolam was associated with higher recurrence (57\% versus $16 \%$ ) and higher mortality (38\% versus 10.5\%).[42][Class II] Studies describe breakthrough seizures and seizures on weaning in $25-50 \%$ of children.

Adverse Effects: Respiratory depression and hypotension. With more prolonged use, midazolam may accumulate, extending the terminal half-life, and tachyphylaxis can occur.

\section{Pentobarbital}

Overview: Pentobarbital is an intravenous anesthetic barbiturate that depresses neuronal excitability by enhancing GABA activity.

Role and Standard Dosage: The recent status epilepticus guideline considers pentobarbital as a refractory treatment option.[1][Class IIB, Level B evidence] Dosing usually involves an initial loading dose of $5-15 \mathrm{mg} / \mathrm{kg}$ (followed by another $5-10 \mathrm{mg} / \mathrm{kg}$ if needed) followed by an infusion at $0.5-5 \mathrm{mg} / \mathrm{kg} /$ hour titrated as needed to achieve seizure suppression or EEG burst suppression. Surveys of epileptologists and critical care physicians in the United States and Europe have reported that barbiturates [43][class IV] and specifically pentobarbital are the treatments of choice for RSE.[44][class IV] One case series of 26 children who received pentobarbital for RSE years provided a loading dose of $5 \mathrm{mg} / \mathrm{kg}$ followed by an infusion of $1-3 \mathrm{mg} / \mathrm{kg} /$ hour. Efficacy was $74 \%$ but $22 \%$ had relapse of seizures upon pentobarbital weaning.[45][Class IV] A case series of 30 patients who received pentobarbital for RSE described sustained burst suppression without relapse in 33\%.[46][Class IV]

Adverse Effects: Respiratory depression, hypotension, cardiac depression, paralytic ileus, infection, and suppression of brainstem reflexes.

Contraindications: Can exacerbate porphyria. 
Main Drug Interactions: Hepatic enzyme inducer.

\section{Ketamine}

Overview: Ketamine is a non-competitive N-methyl D-aspartate (NMDA)-type glutamate receptor antagonist that may be effective in later stages of RSE since it acts independently of GABA- related mechanisms that underlie benzodiazepine and barbiturate function. Additionally, ketamine may be neuroprotective by reducing NMDA receptor mediated excitotoxic injury.

Role and Standard Dosage: The recent status epilepticus guideline considers ketamine as an emerging therapy.[1] Only case reports and series are available reporting $0.5-2 \mathrm{mg} / \mathrm{kg}$ loading doses followed by continuous infusions. The largest case series described 9 children RSE refractory to midazolam, and also refractory to pentobarbital in 5 children. Ketamine was administered at a median of 6 days of RSE at a median dose of $40 \mathrm{mcg} / \mathrm{kg} / \mathrm{min}$, which achieved RSE control in 66\% of children. Responders received ketamine for 3-17 days and generally achieved a burst-suppression EEG pattern. No major adverse effects were reported.[47][Class IV]

Adverse Effects: Some studies have reported increased intracranial pressure with ketamine administration for lumbar puncture sedation.[48][Class IV] In contrast, a literature review did not identify evidence of ketamine-induced elevations in intracranial pressure, instead ketamine administration was associated with improved cerebral perfusion.[49][Class IV] Ketamine's sympathomimetic properties may produce hypertension and tachycardia.

Interactions: Hepatic enzyme inducer and inhibitor.

\section{Propofol}

Overview: Propofol is an intravenous alkyl-phenol general anesthetic thought to modulate GABA receptors that is rapidly acting, easily titrated and has a short half-life with little accumulation.

Role and Standard Dosage: The recent status epilepticus guideline considers propofol to be used as a refractory treatment option [Class IIB, Level B evidence] with an initial 1-2 mg/kg loading dose and initial $20 \mathrm{mcg} / \mathrm{kg} /$ minute infusion titrated up by about $5-10 \mathrm{mcg} / \mathrm{kg} / \mathrm{minute}$ as needed, with caution advised with dosing above $65 \mathrm{mcg} / \mathrm{kg} /$ minute in children.[1] Few data are available. A retrospective study of 33 children with RSE indicated that propofol was more effective than thiopental in terminating seizures (64\% versus $55 \%)$ with a mean propofol treatment duration of 57 hours. Complications including rhabdomyolysis and hypertriglyceridemia prompted discontinuation in $18 \%$ of patients, although these lab values normalized after propofol was discontinued and no deaths were attributable to propofol.[50] [Class IV]

Adverse Effects: Respiratory depression and hypotension. Propofol has been associated with propofol infusion syndrome (cardiac failure, rhabdomyolysis, metabolic acidosis, renal failure, and sometimes death) with risk factors including high-doses, prolonged use 
(although may occur in 1-2 days), supportive treatments with catecholamines and corticosteroids, and possibly with low body mass index. This complication limits the use of propofol in children.[51][Class IV]

\section{Other Therapies}

Isoflurane: May be considered for RSE. Only case reports are available.[52, 53][Class IV] Hypotension requiring vasopressor therapy is common and many patients experience seizure recurrence upon weaning.

Lacosamide: Lacosamide is approved for adjunct treatment of partial seizures in patients older than 17 years and functions by enhancing slow inactivation of voltage-dependent sodium channels. Dosing has not been established in children with status epilepticus, although there is experience using lacosamide in refractory epilepsy in children with initial doses of $1.3 \mathrm{mg} / \mathrm{kg} / \mathrm{day}$ and maintenance doses of $4.7 \mathrm{mg} / \mathrm{kg} / \mathrm{day}$.[54][Class IV] While several case series have described the use of lacosamide in adults with refractory status epilepticus [55][Class IV] only one pediatric case report is available.[56][Class IV] Lacosamide may prolong the PR interval so should be used in caution when there is a concern for cardiac conduction problems.

Pyridoxine: Pyridoxine-dependent seizures are related to a rare autosomal recessive mutation in the ALDH7A1 gene which encodes antiquitin. This condition usually presents in the early neonatal period with seizures that are refractory to standard anticonvulsants. While generally considered in neonates with seizures, there have been reports of older patients including infants and even adults with status epilepticus controlled by pyridoxine.[57-61] [Class IV] The diagnosis of pyridoxine-related seizures is made when administration of intravenous pyridoxine (vitamin B6) (often 100mg given for one to five doses) terminates seizures, sometimes for several months after administration. Some children who do not respond to pyridoxine may respond to oral pyridoxal phosphate.[62][Class IV] Since multiple medications are often being adjusted at the same time, it may be unclear whether a benefit is due to pyridoxine, time, or other co-administered medications once RSE terminates. In the past, pyridoxine would be withdrawn to determine whether seizures recurred and if so, pyridoxine-dependent seizures were diagnosed.[63] This trial-and-error approach may now be avoided by evaluating for elevated urinary alpha-aminoadipic semialdehyde or mutations in the ALDH7A1 gene.[64]

Ketogenic Diet: The ketogenic diet is a high fat, low carbohydrate diet that requires a precise nutrition regimen and can be administered via modified parenteral nutrition solutions or intravenously. While most patients have been treated with oral versions of the diet, intravenous ketogenic diet use has also been reported.[65][Class IV] The ketogenic diet is considered the treatment of choice for GLUT-1 transporter deficiency and pyruvate dehydrogenase deficiency. The ketogenic diet is contraindicated in patients with porphyria, pyruvate carboxylase deficiency, disorders of fatty acid oxidation and metabolism, and some other metabolic disorders. Screening labs include serum acylcarnitine profile, amino acids, lactate, ammonia, complete blood count, electrolytes, liver function tests, and urine organic acids.[66, 67][Class IV] Implementation is complex and multiple adverse effects may occur, 
necessitating an experienced team.[68] Adverse effects include hypoglycemia, metabolic acidosis, fatigue, hypertriglyceridemia, gastroesophageal reflux, emesis, constipation, and nephrolithiasis. Rarer reported adverse effects include esophagitis, renal tubular acidosis, hepatitis, lipoid pneumonia, pancreatitis, and metabolic abnormalities including hypocalcemia, hypomagnesemia, hyponatremia, and hypoproteinemia. Only case reports and series are available regarding the use of the ketogenic diet for RSE. A case series described that the ketogenic diet at a 4:1 ratio with fever induced refractory epileptic encephalopathy was efficacious in 7 of 9 patients in a mean of 4.8 days after starting the diet.[69][Class IV] A recent literature review summarized 32 reported cases in which children and adults with SE were treated with dietary therapy and reported that $78 \%$ became seizure-free, with a response generally occurring in 7-10 days.[68][Class IV]

Immunomodulation: Only a small number of case reports describe the use of corticosteroids, adrenocorticotropic hormone, and plasmapheresis for RSE. Adverse effects include risks of infection with immune suppression, renal complications and aseptic meningitis with IVIG, and hypertension with ACTH. These therapies may be useful in the context of autoimmune or inflammatory etiologies for RSE, such as Rasmussen encephalitis, vasculitis, NMDA receptor encephalitis, or Hashimoto encephalitis.

Resective Epilepsy Surgery: Resective surgery aims to remove the epileptogenic zone based on information derived from EEG and imaging modalities while avoiding injury to eloquent regions. Case reports and series have reported efficacy for lesions including focal cortical dysplasias, hypothalamic hamartomas, cortical tubers, cerebral cavernous malformations, Rasmussen encephalitis, and prenatal infarcts. In some patients, MRI lesions were not evident, but localization was performed using EEG and MEG or PET imaging. Reported procedures include focal resection, lobectomy, multiple subpial transection, hemispherectomy, and corpus callosotomy. A case series of 15 children with RSE who underwent surgical procedures reported that all had seizure control ranging from seizure freedom to substantial reductions, allowing transition out of the ICU.[70][Class IV]

Vagus Nerve Stimulation: Vagus nerve stimulation has been reported effective in several case reports, but efficacy is generally over a prolonged period.

Hypothermia: When used as a neuroprotective strategy for multiple types of brain injury, therapeutic hypothermia may reduce many destructive processes due to excitotoxicity, neuroinflammation, apoptosis, free radical production, seizures, and blood- brain barrier disruption. Only case reports and small case series have described the use of therapeutic hypothermia for status epilepticus, which suggest that $1-5$ days of hypothermia to $32-36^{\circ} \mathrm{C}$ may terminate seizures; often, seizures do not recur upon rewarming and some patients go on to have a favorable outcome. A series of five children with RSE managed with hypothermia $\left(32-35^{\circ} \mathrm{C}\right)$ for $1-5$ days reported RSE termination in all patients, although two of the five had seizures (but not SE) recur after warming. Three of the five were able to return home.[71][Class IV] A report of two children aged 4 and 10 years with febrile infection-related epilepsy syndrome treated with hypothermia $\left(33^{\circ} \mathrm{C}\right)$ within 12 hours of admission had SE termination without recurrence, and both had a Glasgow Outcome Score of 4 (moderate disability) at follow-up.[72][Class IV] Complications include transient 
asymptomatic metabolic changes (hypokalemia, hypernatremia, hyperglycemia, lactic acidosis), asymptomatic coagulopathy, and hemodynamic instability.

Electroconvulsive Therapy: RSE is considered an indication for electroconvulsive therapy by the American Psychiatric Association Task Force Report [73]. Experimental evidence suggests that electroconvulsive therapy may augment endogenous GABA and reduce neuronal metabolic activity, thereby producing a refractory period that can terminate SE. Only case reports and small series are available. A case series of 7 adults and 4 children with RSE reported that electroconvulsive therapy led to improvement in $80 \%$ (often temporarily) and $27 \%$ had full functional recovery.[74][Class IV] Electroconvulsive therapy may also induce seizures and non-convulsive SE, [75, 76][Class IV] so EEG monitoring after electroconvulsive therapy is generally indicated. Preexisting cardiovascular conditions are a relative contraindication to electroconvulsive therapy.

\section{Acknowledgments}

Nicholas Abend is funded by NIH K23NS076550. Dr. Abend has also given expert testimony in medico-legal cases and receives royalties from Demos Medical Publishing for "Pediatric Neurocritical Care."

Tobias Loddenkemper receives support from the National Institutes of Health/NINDS, a Career Development Fellowship Award from Harvard Medical School and Boston Children's Hospital, the Program for Quality and Safety at Boston Children's Hospital, the Payer Provider Quality Initiative, The American Epilepsy Society, The Epilepsy Foundation of America, the Center for Integration of Medicine and Innovative Technology, the Epilepsy Therapy Project, the Pediatric Epilepsy Research Foundation, the Danny Did Foundation, the HHV6 Foundation, and from investigator initiated research grants from Lundbeck and Eisai. Dr. Loddenkemper also serves on the Laboratory Accreditation Board for Long Term (Epilepsy and Intensive Care Unit) Monitoring, on the Council of the American Clinical Neurophysiology Society, on the American Board of Clinical Neurophysiology, as an Associate Editor for Seizure

\section{References}

Papers of particular interest, published recently, have been highlighted as:

- Of importance

•- Of major importance

$1 \bullet$. Brophy GM, Bell R, Claassen J, et al. Guidelines for the evaluation and management of status epilepticus. Neurocrit Care. 2012; 17(1):3-23. This guideline statement discusses the management of status epilepticus in children, including an overall approach, acute medical management, and anti-seizure medications. [PubMed: 22528274]

2. Riviello JJ, Ashwal S, Hirtz D, et al. Practice Parameter: Diagnostic assessment of the child with status epilepticus (an evidence-based review). Neurology. 2006; 67:1542-1550. [PubMed: 17101884]

3. Singh RK, Stephens S, Berl MM, et al. Prospective study of new-onset seizures presenting as status epilepticus in childhood. Neurology. 2010; 74(8):636-42. [PubMed: 20089940]

4. Chin RF, Neville BG, Peckham C, et al. Incidence, cause, and short-term outcome of convulsive status epilepticus in childhood: prospective population-based study. Lancet. 2006; 368(9531):2229. [PubMed: 16844492]

5. Berg AT, Shinnar S, Levy SR, et al. Status epilepticus in children with newly diagnosed epilepsy. Ann Neurol. 1999; 45(5):618-23. [PubMed: 10319884]

6. Eriksson K, Metsaranta P, Huhtala H, et al. Treatment delay and the risk of prolonged status epilepticus. Neurology. 2005; 65(8):1316-8. [PubMed: 16247069] 
7. Lewena S, Young S. When benzodiazepines fail: how effective is second line therapy for status epilepticus in children? Emerg Med Australas. 2006; 18(1):45-50. [PubMed: 16454774]

8. Hayashi K, Osawa M, Aihara M, et al. Efficacy of Intravenous Midazolam for Status Epilepticus in Childhood. Pediatr Neurol. 2007; 36(6):366-372. [PubMed: 17560497]

9. Jacob TC, Moss SJ, Jurd R. GABA(A) receptor trafficking and its role in the dynamic modulation of neuronal inhibition. Nat Rev Neurosci. 2008; 9(5):331-43. [PubMed: 18382465]

10. Goodkin HP, Joshi S, Mtchedlishvili Z, et al. Subunit-specific trafficking of GABA(A) receptors during status epilepticus. J Neurosci. 2008; 28(10):2527-38. [PubMed: 18322097]

11. Pakalnis A, Paolicchi J, Gilles E. Psychogenic status epilepticus in children: psychiatric and other risk factors. Neurology. 2000; 54(4):969-70. [PubMed: 10690994]

12. Papavasiliou A, Vassilaki N, Paraskevoulakos E, et al. Psychogenic status epilepticus in children. Epilepsy Behav. 2004; 5(4):539-46. [PubMed: 15256192]

13. Kirkham FJ, Wade AM, McElduff F, et al. Seizures in 204 comatose children: incidence and outcome. Intensive Care Med. 2012; 38(5):853-62. [PubMed: 22491938]

14. Topjian AA, Gutierrez-Colina AM, Sanchez SM, et al. Electrographic Status Epilepticus is Associated with Mortality and Worse Short-Term Outcome in Critically Ill Children. Critical Care Medicine. 2013; 31:215-223. [PubMed: 23164815]

15. Abend NS, Arndt DH, Carpenter JL, et al. Electrographic seizures in pediatric ICU patients: Cohort study of risk factors and mortality. Neurology. 2013; 81(4):383-391. [PubMed: 23794680]

16. Wagenman KL, Blake TP, Sanchez SM, et al. Electrographic status epilepticus and long-term outcome in critically ill children. Neurology. 2014

17. Payne ET, Zhao XY, Frndova H, et al. Seizure burden is independently associated with short term outcome in critically ill children. Brain. 2014

18. Abend NS, Gutierrez-Colina AM, Topjian AA, et al. Nonconvulsive seizures are common in critically ill children. Neurology. 2011; 76(12):1071-7. [PubMed: 21307352]

19. Williams K, Jarrar R, Buchhalter J. Continuous video-EEG monitoring in pediatric intensive care units. Epilepsia. 2011; 52(6):1130-6. [PubMed: 21671924]

20•. Sanchez Fernandez I, Abend NS, Arndt DH, et al. Electrographic seizures after convulsive status epilepticus in children and young adults. A retrospective multicenter study. Journal of Pediatrics. 2014; 164(2):339-346. This multi-center observational study addresses the use of EEG monitoring in children presenting with status epilepticus. [PubMed: 24161223]

21. Cook AM, Castle A, Green A, et al. Practice variations in the management of status epilepticus. Neurocrit Care. 2012; 17(1):24-30. This study summarizes current practice related to status epilepticus, including variation across institutions. [PubMed: 22565631]

22. Shorvon S, Baulac M, Cross H, et al. The drug treatment of status epilepticus in Europe: Consensus document from a workshop at the first London Colloquium on Status Epilepticus. Epilepsia. 2008; 49(7):1277-1286. [PubMed: 18638280]

23. Tobias JD, Berkenbosch JW. Management of status epilepticus in infants and children prior to pediatric ICU admission: deviations from the current guidelines. South Med J. 2008; 101(3):26872. [PubMed: 18364657]

24. Lewena S, Pennington V, Acworth J, et al. Emergency management of pediatric convulsive status epilepticus: a multicenter study of 542 patients. Pediatr Emerg Care. 2009; 25(2):83-7. [PubMed: 19194344]

25. Chin RF, Verhulst L, Neville BG, et al. Inappropriate emergency management of status epilepticus in children contributes to need for intensive care. J Neurol Neurosurg Psychiatry. 2004; 75(11): 1584-8. [PubMed: 15489391]

26. Tirupathi S, McMenamin JB, Webb DW. Analysis of factors influencing admission to intensive care following convulsive status epilepticus in children. Seizure. 2009; 18(9):630-3. [PubMed: 19699662]

27. Sreenath TG, Gupta P, Sharma KK, et al. Lorazepam versus diazepam-phenytoin combination in the treatment of convulsive status epilepticus in children: A randomized controlled trial. Eur J Paediatr Neurol. 2010; 14(2):162-168. [PubMed: 19297221] 
28. Appleton R, Macleod S, Martland T. Drug management for acute tonic-clonic convulsions including convulsive status epilepticus in children. Cochrane Database Syst Rev. 2008; (3):CD001905. [PubMed: 18646081]

29. McMullan J, Sasson C, Pancioli A, et al. Midazolam versus diazepam for the treatment of status epilepticus in children and young adults: a meta-analysis. Acad Emerg Med. 2010; 17(6):575-82. [PubMed: 20624136]

30. Shaner DM, McCurdy SA, Herring MO, et al. Treatment of status epileticus: a prospective comparison of diazepam and phenytoin versus phenobarbital and optional phenytoin. Neurology. 1988; 38:202-207. [PubMed: 3277082]

31. Crawford TO, Mitchell WG, Fishman LS, et al. Very-high-dose phenobarbital for refractory status epilepticus in children. Neurology. 1988; 38(7):1035-40. [PubMed: 3386819]

32. Wilmshurst JM, van der Walt JS, Ackermann S, et al. Rescue therapy with high-dose oral phenobarbitone loading for refractory status epilepticus. J Paediatr Child Health. 2010; 46(1-2): 17-22. [PubMed: 19943867]

33. Lin JJ, Lin KL, Wang HS, et al. Effect of topiramate, in combination with lidocaine, and phenobarbital, in acute encephalitis with refractory repetitive partial seizures. Brain Dev. 2009; 31(8):605-611. [PubMed: 18993000]

34. Mehta V, Singhi P, Singhi S. Intravenous sodium valproate versus diazepam infusion for the control of refractory status epilepticus in children: a randomized controlled trial. J Child Neurol. 2007; 22(10):1191-7. [PubMed: 17940245]

35. Yu KT, Mills S, Thompson N, et al. Safety and efficacy of intravenous valproate in pediatric status epilepticus and acute repetitive seizures. Epilepsia. 2003; 44(5):724-6. [PubMed: 12752474]

36. Uberall MA, Trollmann R, Wunsiedler U, et al. Intravenous valproate in pediatric epilepsy patients with refractory status epilepticus. Neurology. 2000; 54(11):2188-9. [PubMed: 10851397]

37. McTague A, Kneen R, Kumar R, et al. Intravenous levetiracetam in acute repetitive seizures and status epilepticus in children: experience from a children's hospital. Seizure. 2012; 21(7):529-34. [PubMed: 22722010]

38. Reiter PD, Huff AD, Knupp KG, et al. Intravenous levetiracetam in the management of acute seizures in children. Pediatric Neurology. 2010; 43(2):117-121. [PubMed: 20610122]

39. Kirmani BF, Crisp ED, Kayani S, et al. Role of intravenous levetiracetam in acute seizure management of children. Pediatr Neurol. 2009; 41(1):37-9. [PubMed: 19520272]

40. Akyildiz BN, Kumandas S. Treatment of pediatric refractory status epilepticus with topiramate. Childs Nerv Syst. 2011; 27(9):1425-30. [PubMed: 21442269]

41. Gilbert DL, Gartside PS, Glauser TA. Efficacy and mortality in treatment of refractory generalized convulsive status epilepticus in children: a meta-analysis. J Child Neurol. 1999; 14(9):602-9. [PubMed: 10488906]

42. Singhi S, Murthy A, Singhi P, et al. Continuous midazolam versus diazepam infusion for refractory convulsive status epilepticus. J Child Neurol. 2002; 17(2):106-10. [PubMed: 11952069]

43. Holtkamp M, Masuhr F, Harms L, et al. The management of refractory generalised convulsive and complex partial status epilepticus in three European countries: a survey among epileptologists and critical care neurologists. J Neurol Neurosurg Psychiatry. 2003; 74(8):1095-9. [PubMed: 12876241]

44. Claassen J, Hirsch LJ, Mayer SA. Treatment of status epilepticus: a survey of neurologists. J Neurol Sci. 2003; 211(1-2):37-41. [PubMed: 12767495]

45. Kim SJ, Lee DY, Kim JS. Neurologic outcomes of pediatric epileptic patients with pentobarbital coma. Pediatr Neurol. 2001; 25(3):217-20. [PubMed: 11587876]

46. Barberio M, Reiter PD, Kaufman J, et al. Continuous infusion pentobarbital for refractory status epilepticus in children. J Child Neurol. 2012; 27(6):721-6. [PubMed: 22156786]

47. Rosati A, L'Erario M, Ilvento L, et al. Efficacy and safety of ketamine in refractory status epilepticus in children. Neurology. 2012; 79(24):2355-8. [PubMed: 23197747]

48. Ben Yehuda Y, Watemberg N. Ketamine increases opening cerebrospinal pressure in children undergoing lumbar puncture. J Child Neurol. 2006; 21(6):441-3. [PubMed: 16948925]

49. Himmelseher S, Durieux ME. Revising a dogma: ketamine for patients with neurological injury? Anesth Analg. 2005; 101(2):524-34. table of contents. [PubMed: 16037171] 
50. van Gestel JP, Blusse van Oud-Alblas HJ, Malingre M, et al. Propofol and thiopental for refractory status epilepticus in children. Neurology. 2005; 65(4):591-2. [PubMed: 16116121]

51. Niermeijer JM, Uiterwaal CS, Van Donselaar CA. Propofol in status epilepticus: little evidence, many dangers? J Neurol. 2003; 250(10):1237-40. [PubMed: 14586609]

52. Kofke WA, Young RS, Davis P, et al. Isoflurane for refractory status epilepticus: a clinical series. Anesthesiology. 1989; 71(5):653-9. [PubMed: 2817458]

53. Mirsattari SM, Sharpe MD, Young GB. Treatment of refractory status epilepticus with inhalational anesthetic agents isoflurane and desflurane. Arch Neurol. 2004; 61(8):1254-9. [PubMed: 15313843]

54. Guilhoto LM, Loddenkemper T, Gooty VD, et al. Experience with lacosamide in a series of children with drug-resistant focal epilepsy. Pediatr Neurol. 2011; 44(6):414-9. [PubMed: 21555051]

55. Hofler J, Trinka E. Lacosamide as a new treatment option in status epilepticus. Epilepsia. 2013; 54(3):393-404. [PubMed: 23293881]

56. Shiloh-Malawsky Y, Fan Z, Greenwood R, et al. Successful treatment of childhood prolonged refractory status epilepticus with lacosamide. Seizure. 2011; 20(7):586-8. [PubMed: 21474342]

57. Yoshii A, Takeoka M, Kelly PJ, et al. Focal status epilepticus as atypical presentation of pyridoxine-dependent epilepsy. J Child Neurol. 2005; 20(8):696-8. [PubMed: 16225819]

58. Goutieres F, Aicardi J. Atypical presentations of pyridoxine-dependent seizures: a treatable cause of intractable epilepsy in infants. Ann Neurol. 1985; 17(2):117-20. [PubMed: 3977296]

59. Chou ML, Wang HS, Hung PC, et al. Late-onset pyridoxine-dependent seizures: report of two cases. Zhonghua Min Guo Xiao Er Ke Yi Xue Hui Za Zhi. 1995; 36(6):434-7. [PubMed: 8592931]

60. Kluger G, Blank R, Paul K, et al. Pyridoxine-dependent epilepsy: normal outcome in a patient with late diagnosis after prolonged status epilepticus causing cortical blindness. Neuropediatrics. 2008; 39(5):276-9. [PubMed: 19294602]

61. Russell KE, Mulligan SR, Mallory LA. Diagnosis of pyridoxine-dependent seizures in a nineteenyear-old patient. Pediatr Neurol. 2012; 47(2):141-3. [PubMed: 22759694]

62. Wang HS, Kuo MF, Chou ML, et al. Pyridoxal phosphate is better than pyridoxine for controlling idiopathic intractable epilepsy. Arch Dis Child. 2005; 90(5):512-5. [PubMed: 15851435]

63. Gospe SM Jr. Pyridoxine-dependent seizures: new genetic and biochemical clues to help with diagnosis and treatment. Curr Opin Neurol. 2006; 19(2):148-53. [PubMed: 16538088]

64. Yeghiazaryan NS, Zara F, Capovilla G, et al. Pyridoxine-dependent epilepsy: an under-recognised cause of intractable seizures. J Paediatr Child Health. 2012; 48(3):E113-5. [PubMed: 21496129]

65. Strzelczyk A, Reif PS, Bauer S, et al. Intravenous initiation and maintenance of ketogenic diet: Proof of concept in super-refractory status epilepticus. Seizure. 2013; 22(7):581-3. [PubMed: 23597842]

66. Cervenka MC, Kossoff EH. Dietary treatment of intractable epilepsy. Continuum (Minneap Minn). 2013; 19(3 Epilepsy):756-66. [PubMed: 23739109]

67. Nordli, DR.; De Vivo, DC. The Ketogenic Diet. In: Wyllie, E., editor. Wyllie's Treatment of Epilepsy. 5. Lippincott, Williams \& Wilkins; Philadelphia, PA: 2011. p. 790-796.

68. Kossoff EH, Nabbout R. Use of dietary therapy for status epilepticus. J Child Neurol. 2013; 28(8): 1049-51. [PubMed: 23640913]

69. Nabbout R, Mazzuca M, Hubert P, et al. Efficacy of ketogenic diet in severe refractory status epilepticus initiating fever induced refractory epileptic encephalopathy in school age children (FIRES). Epilepsia. 2010; 51(10):2033-2037. [PubMed: 20813015]

70. Bhatia S, Ahmad F, Miller I, et al. Surgical treatment of refractory status epilepticus in children. J Neurosurg Pediatr. 2013; 12(4):360-6. [PubMed: 23971636]

71. Guilliams K, Rosen M, Buttram S, et al. Hypothermia for pediatric refractory status epilepticus. Epilepsia. 2013

72. Lin JJ, Lin KL, Hsia SH, et al. Therapeutic hypothermia for febrile infection-related epilepsy syndrome in two patients. Pediatr Neurol. 2012; 47(6):448-50. [PubMed: 23127267] 
73. Weiner, RD.; Coffet, CE.; Fochtmann, L. The Practice of ECT: Recommendations for Treatment, Training and Privileging. 2. Washington DC: American Psychiatric Press; 2001.

74. Lambrecq V, Villega F, Marchal C, et al. Refractory status epilepticus: electroconvulsive therapy as a possible therapeutic strategy. Seizure. 2012; 21(9):661-4. [PubMed: 22877995]

75. Cristancho MA, Alici Y, Augoustides JG, et al. Uncommon but serious complications associated with electroconvulsive therapy: recognition and management for the clinician. Curr Psychiatry Rep. 2008; 10(6):474-80. [PubMed: 18980730]

76. Srzich A, Turbott J. Nonconvulsive generalised status epilepticus following electroconvulsive therapy. Aust N Z J Psychiatry. 2000; 34(2):334-6. [PubMed: 10789539] 